Dhaka Univ. J. Biol. Sci. 29(1): 53-59, 2020 (January)

\title{
FACTORS INFLUENCING CONSUMER DECISION MAKING FOR PERSONAL CARE PRODUCTS
}

\author{
Md Salim Hossain and NasRin Sultana SHILA* \\ Department of Psychology, University of Dhaka, Dhaka-1000, Bangladesh
}

Key words: Consumer decision making, Personal care products, Marketers

\begin{abstract}
Personal care products are part of our everyday life and it is a large industry. It is very important for marketers to know what consumers give importance to when they buy these products. It will help them to produce, design and promote products focusing consumer's need and attract more consumers. This work is a cross-sectional survey which focuses on choice opinions of consumers of Dhaka city. Primary data were collected from 300 people using a 15 item questionnaire with 5 point Likert scale. Analysis shows mean rank of 6 factors (Specialized product, $\mathrm{M}=3.953$, rank 1 to word of mouth, $M=2.200$, rank 6), significant difference in one tailed $t$ test between male and female in factor 1- specialized products $\left(t_{c}=4.702>t_{t}=1.65\right)$ and different mean rank among people from 5 different professions (for student, service holder and businessman, rank 1 - specialized products; for unemployed and housewife, rank 1 - characteristics of product). Present study also explored opinions of people having different education levels but did not find any significant difference.
\end{abstract}

\section{Introduction}

Personal care products include cleansing, styling, shaving, skin and hair care products, perfume, deodorant and make-up items. This industry plays a big role in economy. According to a report of Japan Bangladesh Business Center, in Bangladesh, the cosmetics and toiletries market worth around 4000 corers $\mathrm{BDT}^{(1)}$. As the profit and loss of this industry largely depends on which products are used by the consumers and which they reject, it is important to know how they make such decisions.

Consumer decision making is an intricate process that includes three main stepsinput, process and output. Marketing strategies and socio-cultural environment influence people before they make actual decision by - need recognition, pre-purchase search and evaluation of alternatives. Present study focuses on pre-purchase search and aims to specifically find out which characteristics of a personal care product is important for a consumer who lives and buys products from different places of Dhaka city.

\footnotetext{
*Author for correspondence: <nasrinshila1995@gmail.com>.
} 
Literature review: As personal care products are important in our daily lives and for the economy, many researches have been conducted in this field. Surprisingly, many findings are quite similar across various nations with different cultures, like Saudi Arabia, India, Taiwan and Finland.

Poranki and Perwej(2) studied buying attitudes of consumers of cosmetic products in Saudi Arabia and found that monthly income of the family does not have any influence on their attitude, housewives have positive attitude towards cosmetic products than working women. Several studies in different states of India also show similar findings, such as, Poranki( ${ }^{(3)}$ studied consumer perception in Visakhapatnam and found that customers like best quality product on any price. Bhatt and Sankhla ${ }^{(4)}$ worked on consumer buying behavior in Gujrat and found that quality is the major motivating factor to prefer one cosmetic brand over another. Chen et al.(5) carried out a study in Taiwan and also found that quality of skin care product affect purchase intention of consumers. Jawahar and Tamizhjyothi ${ }^{(6)}$ studied consumer attitude in Annamalainagar and also found that people are more conscious about quality, value for money and branding of cosmetic products. Desai ${ }^{(7)}$ found in Kolhapur that $85 \%$ people preferred quality of product, where $10 \%$ considered brand name and only 3\% considered price. Isa ${ }^{(8)}$ did a thesis on Finnish women regarding facial skin care products and also found that for women aged 20 to 60 years, quality and suitability to skin is more important than affordability.

Present study has combined all these factors from studies done in different nations and cultures and considered them extensively in the context of Dhaka city.

Rationale of the study: From literature review, it can be seen that, previous researches were mainly focused on budget, quality and brand. But how these factors influence consumers of our city or whether different factors influence different types of consumers were not studied. That is why present study focused on four different issues regarding personal care products which are important for our cosmetics and toiletries market.

- Marketers generally advertise their products focusing on brand name or specific effect or price of the product and new products are also regularly introduced in this already existing wide variety of products. So, present study aims to find out among these, which factors are most important to consumers while buying personal care products.

- From shampoo to soap to body spray, almost every kind of personal care products have different products for men and women. So, present study aims to find out whether there is any difference in opinion regarding personal care products in males and females.

- Some marketers focus on the profession their models are playing on advertisement of products or they chose successful persons of different professions to present their 
products. So, present study aims to find out whether there is any difference in opinion regarding personal care products among people from different professions.

- Education makes people more aware and sensible about one's surroundings. So, present study aims to find out whether education changes people's opinion about personal care products or whether there is any difference in opinion regarding personal care products in people having different levels of education.

Objectives of the study: From the rationale of the study it is very clear that the present study aims to find out four things:

- Influence of factors while buying personal care products.

- Whether there is any difference in opinion regarding personal care products in men and women.

- Whether there is any difference in opinion regarding personal care products among people from different professions.

- Whether there is any difference in opinion regarding personal care products in people having different levels of education.

\section{Materials and Methods}

Participants: All participants of this study are resident of Dhaka. Their age range is 20 to 40 years and all of them are literate. Based on Cochran's Sample Size Formula (1977)(9), 68 participants were enough for generalization with $90 \%$ confidence interval for overall population of Dhaka city, but data were collected from 300 participants so that there are enough participants in each sub category of gender, profession and education for further analyses. Distribution of sample is presented in Table 1 in detail.

Table 1. Distribution of sample.

\begin{tabular}{|c|c|c|c|c|c|c|}
\hline & \multicolumn{2}{|l|}{ Gender } & \multicolumn{2}{|l|}{ Occupation } & \multicolumn{2}{|l|}{ Education } \\
\hline & Male & 121 & Unemployed & 2 & HSC & 47 \\
\hline & Female & 179 & Student & 233 & Graduation & 177 \\
\hline & & & Service holder & 17 & Post graduation & 76 \\
\hline & & & Housewife & 10 & & \\
\hline & & & Business person & 38 & & \\
\hline Total & & 300 & & 300 & & 300 \\
\hline
\end{tabular}

Sampling technique: Two-stage cluster sampling technique was used. Here, population of Dhaka city was divided into clusters using geographic boundary of ward, so it can also be called area sampling or geographic cluster sampling. Among 93 wards of Dhaka city (target population), participants (secondary sampling unit) were chosen from 38 randomly selected wards (primary sampling unit). 
Materials: Data was collected using a 15 item questionnaire with 5 point Likert scale response option and Personal Information Form developed by researcher.

Twenty six statements were written under 6 different categories (budget, expensive or branded products, characteristics of product, new product, specialized product, word of mouth) based on previous studies. These categories were written as questions and the statements as probable answers. This primary questionnaire was sent to 7 raters for judging content validity by Lawshe's Content Validity Ratio(10) and inter-rater reliability by Percent Agreement method ${ }^{(11)}$. Fifteen statements were selected for final questionnaire based on fulfillment of two conditions - exceeding CVR critical value and at least $85 \%$ agreement. Then 5 point Likert scale response option was added to turn them into a questionnaire. Personal Information Form (PIF) with 6 items (name, age, gender, profession, education level, address) was developed to collect demographic data needed for analysis.

Procedure: To collect data for this cross-sectional survey, a Google form was created based on the questionnaire and PIF. It was sent to approximately 500 people online who live in the 38 randomly selected wards. Their address was confirmed by social media and personal connection of the researcher. Among them, 300 responded with completely fulfilled questionnaire. Each participant needed about 5 minutes to fill up the form. Then their responses were recorded in Microsoft Office Excel 2007 and first used for factor analysis in IBM SPSS 20 for further validation of the questionnaire. According to its result, scoring of item number 7 was reversed. It also shows that Factor 1 includes item number 4, 8, 10 and 13, Factor 2 includes item number 2, 5 and 9, Factor 3 includes item number 3 and 6, Factor 4 includes item number 1, 12 and 14, Factor 5 includes item number 11 and 15 and Factor 6 includes item number 7. As this Likert scale has more than 4 Likert type items that are combined into a single variable ${ }^{(12)}$ (consumer buying behavior), interval level analysis methods were used. Mean was calculated of each factor for ranking them in descending order and for administering $t$ test.

\section{Results and Discussion}

Result of the present study is presented in 4 tables. Table 2 shows that specialization (rank 1) and characteristics of products (rank 2) are the most important factor for personal care products. People give them more importance than budget (rank 5). People are ready to spend for expensive products (rank 3) even if they do not have recommendation for the product (rank 6). All the previous researches also show that quality of the product is more important to consumers than price.

Table 3 shows the results of one tailed $t$ test for each factor where, $\alpha=0.05, \mu_{1}=$ mean of female and $\mu_{2}=$ Mean of male. Most of the previous studies in this field were done with only female participants. Although some studies had both male and female participants, only the study by Chen et al. showed difference between male and female 
consumers. Though in Taiwan women were found to be influenced by price and men by the feeling of using the product; present study that in Dhaka shows that females are more concerned about specialized products than men. It means they care more about whether the product is specially made for their hair or skin type or how it will benefit them. Marketers can use this information for positioning and promoting products specially made for male and female consumers.

Table 2. Mean rank of factors based on choice opinion of all participants.

\begin{tabular}{|c|c|c|c|c|c|}
\hline Factors & $\mathrm{N}$ & Sum & $\mathrm{Sd}$ & Mean & Rank \\
\hline Specialized product & & 1186.00 & 0.715 & 3.953 & 1 \\
\hline Characteristics of product & & 1063.67 & 0.815 & 3.546 & 2 \\
\hline Expensive or branded product & 300 & 1020.33 & 0.909 & 3.401 & 3 \\
\hline New product & & 906.50 & 0.934 & 3.022 & 4 \\
\hline Budget & & 854.50 & 1.131 & 2.848 & 5 \\
\hline Word of mouth & & 660.50 & 1.069 & 2.200 & 6 \\
\hline
\end{tabular}

Table 3. Result of one tailed $t$ test $\left(\mathrm{H}_{1}: \mu_{1}>\mu_{2}\right)$ at $95 \%$ confidence interval.

\begin{tabular}{|c|c|c|c|c|}
\hline Factors & Table value of $\mathrm{t}$ & $\mathrm{df}$ & Calculated value of $t$ & Decision \\
\hline Specialized product & & & 4.702 & $\mu_{1}>\mu_{2}$ \\
\hline Expensive or branded product & & & 1.235 & $\mu_{1}=\mu_{2}$ \\
\hline Budget & 1.65 & 298 & 0.428 & $\mu_{1}=\mu_{2}$ \\
\hline Characteristics of product & & & 1.013 & $\mu_{1}=\mu_{2}$ \\
\hline New product & & & 0.327 & $\mu_{1}=\mu_{2}$ \\
\hline Word of mouth & & & -1.529 & $\mu_{1}=\mu_{2}$ \\
\hline
\end{tabular}

Table 4 shows that different professionals give more importance to different factors. The most important factor for students, service holders and businessman is specialization of products where characteristics of products; such as ingredients is most important for housewives and unemployed people. Suggestion of other people or word of mouth is the least important factor for people of other professions except students. To students, expensive or branded product is the least important factor. Budget or price of the product is more important to unemployed people (rank 3) and students (rank 4) than service holder, housewife and businessman (rank 5). Though some researchers have studied difference in opinion between housewives and employed women ${ }^{(3)}$ and difference among working people, housewives and students(7), present study has more extensively studied this aspect and have found these new information.

Table 5 shows that people having different educational level prefer the same factors in case of personal care products. Though the present study has considered this new 
dimension which was not explored before but in this case, all participants were literate and quite highly educated as their lowest level of education is higher secondary. If difference between illiterate and literate people or difference between people having huge gap in educational background, such as people with primary and post graduation level of education can be studied, some differences in opinion might come out.

Table 4. Mean rank of factors based on different professions.

\begin{tabular}{|c|c|c|c|c|c|c|c|c|c|c|}
\hline & \multicolumn{2}{|c|}{ Unemployed } & \multicolumn{2}{|c|}{ Student } & \multicolumn{2}{|c|}{ Service holder } & \multicolumn{2}{|c|}{ Housewife } & \multicolumn{2}{|c|}{ Businessman } \\
\hline & Mean & Rank & Mean & Rank & Mean & Rank & Mean & Rank & Mean & Rank \\
\hline Specialized product & 3.75 & 2 & 3.97 & 1 & 3.82 & 1 & 3.88 & 2 & 3.97 & 1 \\
\hline $\begin{array}{l}\text { Characteristics of } \\
\text { product }\end{array}$ & 4.00 & 1 & 3.56 & 2 & 3.55 & 2 & 4.17 & 1 & 3.36 & 2 \\
\hline $\begin{array}{l}\text { Expensive or } \\
\text { branded product }\end{array}$ & 3.00 & 4 & 0.72 & 6 & 3.24 & 4 & 3.37 & 4 & 3.23 & 3 \\
\hline New product & 2.50 & 5 & 2.99 & 3 & 3.38 & 3 & 3.75 & 3 & 2.92 & 4 \\
\hline Budget & 3.25 & 3 & 2.84 & 4 & 3.09 & 5 & 2.95 & 5 & 2.76 & 5 \\
\hline Word of mouth & 1.50 & 6 & 2.23 & 5 & 1.94 & 6 & 2.20 & 6 & 2.18 & 6 \\
\hline
\end{tabular}

Table 5. Mean rank of factors based on education level.

\begin{tabular}{lcccccccc}
\hline & \multicolumn{3}{c}{ HSC } & & \multicolumn{2}{c}{ Graduation } & & \multicolumn{2}{c}{ Post graduation } \\
\cline { 2 - 3 } & Mean & Rank & & Mean & Rank & & Mean & Rank \\
\hline Specialized product & 3.97 & 1 & & 3.96 & 1 & & 3.92 & 1 \\
Characteristics of product & 3.51 & 2 & & 3.57 & 2 & & 3.50 & 2 \\
Expensive or branded product & 3.45 & 3 & & 3.40 & 3 & & 3.37 & 3 \\
New product & 3.13 & 4 & & 2.94 & 4 & & 3.16 & 4 \\
Budget & 2.94 & 5 & & 2.76 & 5 & & 2.99 & 5 \\
Word of mouth & 2.06 & 6 & & 2.23 & 6 & & 2.22 & 6 \\
\hline
\end{tabular}

Though personal care products are essential part of our daily life and national economy, very little research has been done on this matter in our country. But research is important in every step of the life cycle of a product. Present study has explored various factors influencing consumers in general as well as consumers with different backgrounds.

These findings can be helpful for marketers to make decisions about design and marketing of the product, promotion of new product or exclusive offer and positioning of new products as well as repositioning of existing products. For example, present study shows that quality and characteristics of the product is more important to consumers than price of the product; so, in promotion, campaign or advertisements of products marketers may focus on effects of the products rather than advertising how cheap it is. 
This study also shows that consumers, especially female consumers are more concerned about specialized products, so while promoting a product marketers can focus on how the product is especially made for women or how it is made for specific type of skin or hair which will attract more consumers.

Though present study explored some new areas but there are some limitations of this study, such as, media play significant role in marketing of a product, but it was not considered here. Also, as mentioned earlier, the difference of opinion between literate and illiterate people might bring out some interesting findings which were also not explored in this study.

\section{References}

1. Ahamed M 2010. A Report on Cosmetic and Toiletries Industries of Bangladesh, Research Department, Japan Bangla Business Center Corporation.

2. Poranki, KR and A. Perwej, 2014. The buying attitudes of consumers of cosmetic products in Saudi Arabia. Research Journal of Social Science \& Management 04: 138-145

3. Poranki, KR 2015. Consumer attitudes and perception on personal care products and cosmetics at Visakhapatnam, India. Research Journal of Social Science \& Management 05: $220-225$

4. Bhatt $\mathrm{K}$ and P. Sankhla 2017. A study on consumer buying behavior towards cosmetic products. International Journal of Engineering Technology Science and Research 4(12): 2394-3386

5. Chen H, Lee Y, Tu Y and Chao Y 2015. Consumer purchase intention for skin-care products. Retrieved from http://www.semanticscholar.org/paper

6. Jawahar, JV and K Tamizhjyothi 2013. Consumer attitude towards cosmetic products. International Journal of Engineering and Management Research. 3(6): 2249-2585

7. Desai K 2014. A study on consumer buying behaviour of cosmetic products in kolhapu. Reviews of Literature 1(10): 2347-2723

8. Isa K 2011. Female buying behavior related to facial skin care products. Hagga-Helia University of Applied Sciences, Finland

9. Cochran WG 1977. Sampling techniques (3rd edition). New York. John Wiley \& Sons.

10. Ayre C and AJ Scally 2014. Critical Values for Lawshe's content validity ratio: Revisiting the original methods of calculation, measurement and evaluation in counseling and development 47(1): 79-86

11. McHugh ML 2012. Interrater reliability: The kappa statistic. Biochemia Medica 22(3): 276-282

12. Boone HN and DA Boone 2012. Analyzing Likert data. Journal of Extention. 50(2) 